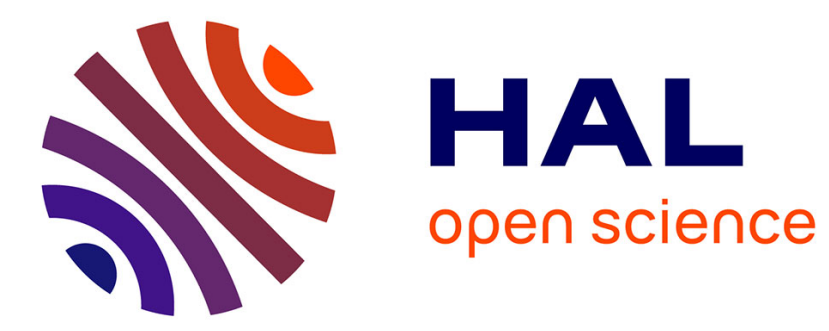

\title{
Development of an Automated Guidance System for Tracked Combine Harvester
}

Fangming Zhang, Wenbin Wu, Yunfei Zhu

\section{To cite this version:}

Fangming Zhang, Wenbin Wu, Yunfei Zhu. Development of an Automated Guidance System for Tracked Combine Harvester. 11th International Conference on Computer and Computing Technologies in Agriculture (CCTA), Aug 2017, Jilin, China. pp.389-399, 10.1007/978-3-030-06179-1_39 . hal02111552

\section{HAL Id: hal-02111552 \\ https://hal.inria.fr/hal-02111552}

Submitted on 26 Apr 2019

HAL is a multi-disciplinary open access archive for the deposit and dissemination of scientific research documents, whether they are published or not. The documents may come from teaching and research institutions in France or abroad, or from public or private research centers.
L'archive ouverte pluridisciplinaire HAL, est destinée au dépôt et à la diffusion de documents scientifiques de niveau recherche, publiés ou non, émanant des établissements d'enseignement et de recherche français ou étrangers, des laboratoires publics ou privés. 


\title{
Development of An Automated Guidance System
}

\section{for Tracked Combine Harvester}

\author{
Zhang Fangming $^{1(\bowtie)}$, Wu Wenbin ${ }^{2}$, Zhu Yunfei ${ }^{3}$ \\ ${ }^{1}$ Ningbo Institue of technolgy, Zhejinag University, Ningbo, China; \\ fangmingzhang@126.com \\ ${ }^{2}$ Ningbo Microagri Technology Ltd., Ningbo,China \\ 1979534947@qq.com \\ 3 Thinker Agricultural Machine ltd.,Huzhou, China \\ 642992007@qq.com
}

\begin{abstract}
An automated guidance system for tracked combine harvesters had been developed. A kinematics model for the harvester is constructed. A conventional and a X-turn path planning methos were provided. The system was successfully controlled speed, direction, and header of 2 modified harvesters, which had harvested 16 acres of rice land in December of 2015 and 2016 . Results showed these machines can accurately cut along the edge of the cut/uncut, and cut all crops in every working path. The lateral offset is less than $5 \mathrm{~cm}$ in row following stage. In future, cutter, threshing roller, and other important working parts must be monitored to realize unmanned technology.
\end{abstract}

Keywords: tracked combine harvester, guidance system, speed control, path planning.

\section{Introduction}

Rubber tracked combine harvesters are wildly used for harvesting rice in China, however the work condition is filled with loud noise and flying dust, which results in short of labours in recent years. Farmers have great thirst for unmanned technology for combines. The domestic and overseas scholars had done a lot researches on automated guidance technology for tractors[1,2,3,4,5] and transplanters[6,7], thus computer aided steering system for tractors have been commercial applied for nearly 15 years. He et al.[8] developed an automatic steering system for a tracked construction machinery through a remote control, whose functions were turning control, speed control, braking control with electro-hydraulic control system, but it lacks the ability of autonomous navigation.

Bound by weight, the volume of a harvester container is around 1200 liters only, that is the harvester must unload grains after working 300 meters. When working in a paddy field with length of 150 meters, the harvester surrounds an area with some width, that it harvests from outer U-ring to inner ones till all crops inside this area are cut. The machine keeps repeating the process from the outside to the inside in the rest of the land, which is the demand should be satisfied by an automatic guidance system. The objective of this research is to develop an automated guidance system for labour saving of tracked combine harvesters that computer will replace human operator to drive a combine to move forward or backward, to stop, to lift or drop the header.

Fangming Zhang,Ningbo Institue of technolgy, Zhejinag University, Ningbo, China. 


\section{Experiments and Methods}

\subsection{Kinematics Model and the Navigation System}

As tracked vehicles use the principle of differential speeds between two rubber tracks to rectify any deviation, the kinematics model is drawn in Fig. 1. If position of the vehicle is $\left(x_{k}, y_{k}\right)$, moving in the path $P_{n}$, the kinematic equation is:

$$
\begin{aligned}
& x_{k+1}=x_{k}+T v_{k} \sin \psi_{k} \\
& y_{k+1}=y_{k}+T v_{k} \cos \psi_{k}
\end{aligned}
$$

where $T$ is acquisition cycle of attitude data, which is 0.2 second here, and $v_{k}$ is speed of the central point, and $\psi_{k}$ is heading angle.

A Kalman filter can be established like Ref. [7], whose state vector is $X=\left[x_{k}, y_{k}, v_{k}, \psi_{k}\right]^{T}$, and measurement vector is $Y=\left[x_{G P S}, y_{G P S}, v_{G P S}, \psi_{G P S}\right]^{T}$. Lateral deviation and heading deviation could get after comparing with path $P_{n}$.

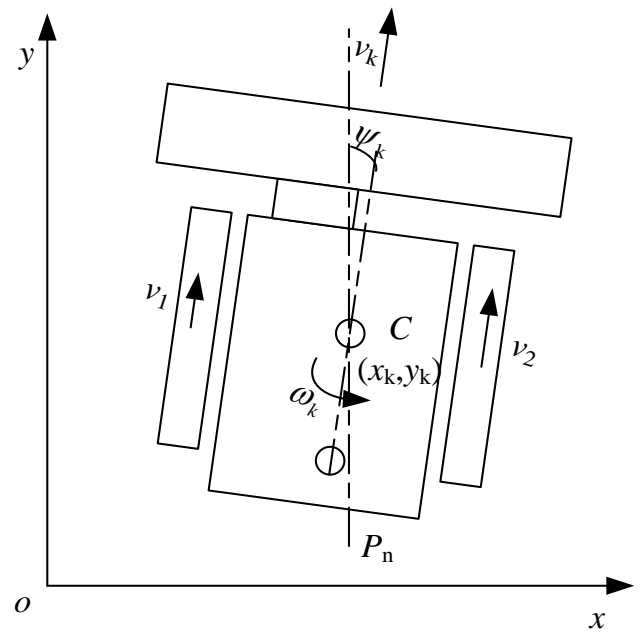

Fig. 1. The kinematics model of a tracked combine harvester

The guidance system consists of an electronic system and mechanical parts, shown in Fig. 2. The electronic system includes a navigation controller, 3 ECUs, a RTK-GPS receiver (Beidou, BD683), and a gyro (Luche, ASV940). The mechanical parts are an electro-hydraulic valve and a motor-driven speeder. The navigation controller adopts Arm-Cortex board (Emtrix, EM335X) and embedded Linux operating system platform, whose software is divided into man machine interface (MMI) and guidance control software(GCS). The ECU1 transfers the data of RTK-GPS and gyro, and the ECU2 controls the electro-hydraulic valve, and the ECU3 controls the motor driven speeder. The double antenna of the RTK-GPS produces precise heading angle with $0.2 \%$ m. The gyro provides pitch and roll angles for positioning correction on uneven paddy land[7]. 


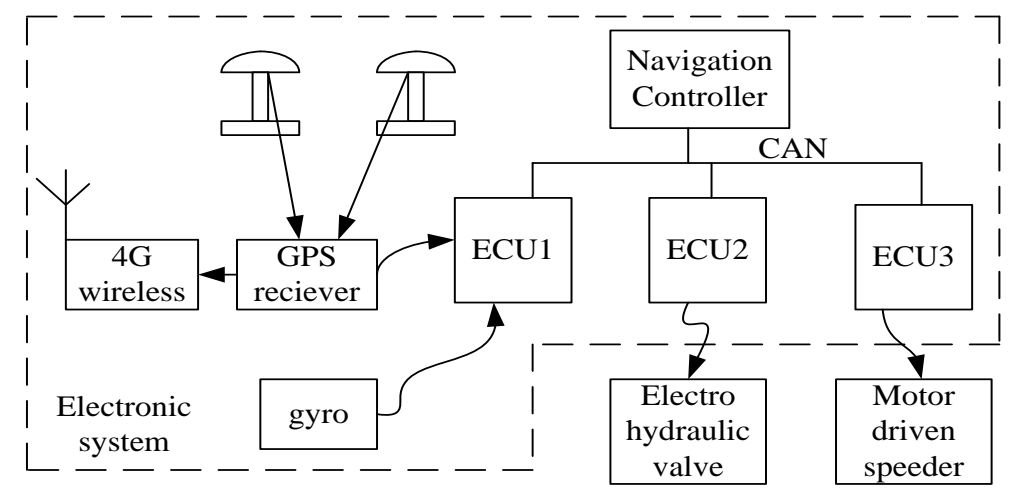

Fig. 2. System structure

\subsection{The electro-hydraulic system for steering control}

A new integrated electro-hydraulic valve, consists of components inside dotted-line rectangle as shown in Fig. 3, was installed into the harvester to control the steering cylinder and the head cylinder. When all valves are in normal position, oil flows through back to oil tank directly, and the head cylinder (5) keeps the header, and the steering cylinder (6) is in its initial position. When the valve A (2) acts, the header cylinder lifts up the header or descends it steadily. When the valve B (7) acts, the steering cylinder pushes the left or right clutch, which produces left turning or right turning. When the solenoid valve (8) is in normal position, a steering command makes a big turning, otherwise, the throttling pathway makes a small turning, whose heading regulating is relatively small and smooth, mainly used in row following control.

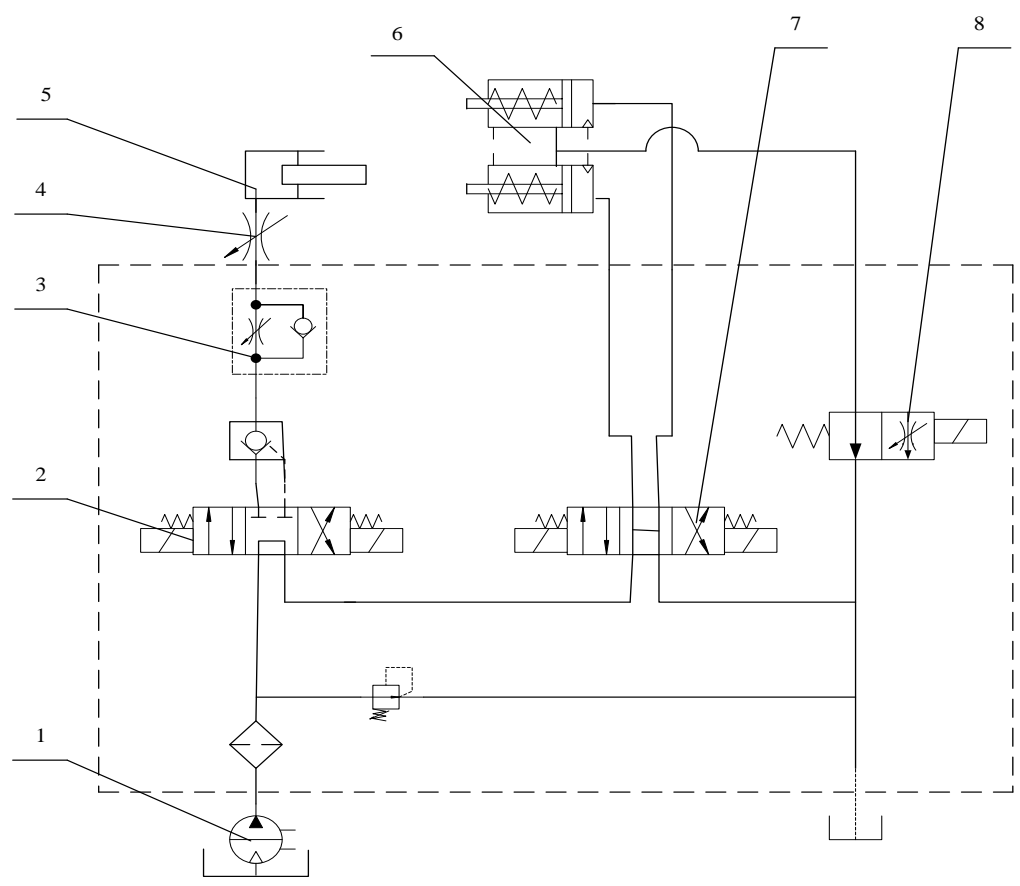

1. pump, 2. electro-four-way three-position directional valve A, 3. one-way throttle valve, 4. manual throttle valve, 5 . head cylinder, 6 . steering cylinder, 7. electro-four-way three-position directional valve $\mathrm{B}, 8$. solenoid valve

Fig. 3. Diagram of electro-hydraulic steering control

\subsection{The Motor-driven Speeder}

Speed control of harvester, aiming at reduced the labor strength and increased the harvesting efficiency, attracted some Chinese scholars to do research. Such as Chen et al.[9] built multivariate fusion reference models under adaptive control and the fuzzy 
control rules to control the speed. The objective of speed control of this project is realizing unmanned driving, that is the harvester needs to change speed, stop and reverse in the course of automated guidance control. It made use of infinitely variable speed control of HST (HydroStaticTransmission).

The motor-driven speeder, shown in Fig. 4, consists of electronic joystick, step motor reducer and a crank connecting rod mechanism. Inside the electronic joystick, the ECU3 controls the rotation of the step motor, thus changes rotation angle of extended shaft of HST. The speeder is initialized with manual control, that the joystick could control vehicle speed with its different position. The speeder could also controlled by commands through the CAN interface of the ECU3.

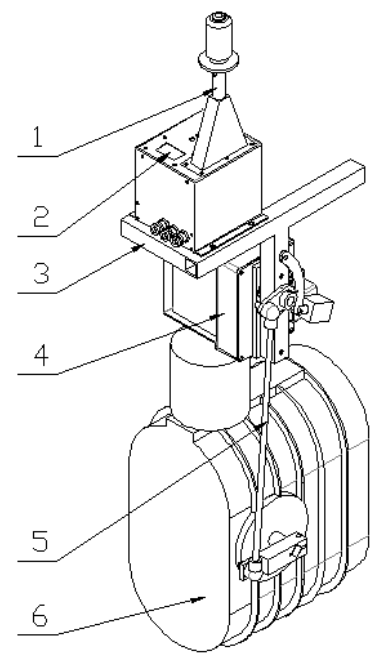

1. electronic joystick, 2. digital display, 3. frame, 4. step motor reducer, 5. crank connecting rod mechanism 6.HST

Fig. 4. HST electric control system

\subsection{Path Planning}

In theory harvesting crops is a coverage task with sequential operation without any repetition. Galceran[10] presented a survey on coverage path planning methods. However, paths at each end of roads have to be overlapped for higher efficiency. Fig. 5 shows a conventional path planning for combine harvester. Here, a local coordinate system is set up after measuring point " $\mathrm{A}$ ", " $\mathrm{B}$ ", and " $\mathrm{C}$ ". The original point is point " $\mathrm{A}$ ", and the $\mathrm{y}$ axis is overlapped with path $P_{F 0}$, and $\mathrm{x}$ axis is in right direction. The length and width of this subregion are:

$$
\begin{aligned}
& L_{A}=L_{G P S}+L_{R}+L_{F}+R \\
& W_{A}=2 N \cdot L_{W}
\end{aligned}
$$

Where $L_{A}$ is Length of the subregion, and $W_{A}$ is width, and $L_{G P S}$ is distance from point A to point $\mathrm{B}$, and $R$ is turning radio of this vehicle, and ${L_{F}}_{F}$ and $L_{R}$ are distance between the GPS to head, back of the vehicle respectively, and $N$ is number of coverage cycl es, usually is set to $4-8$ rings 


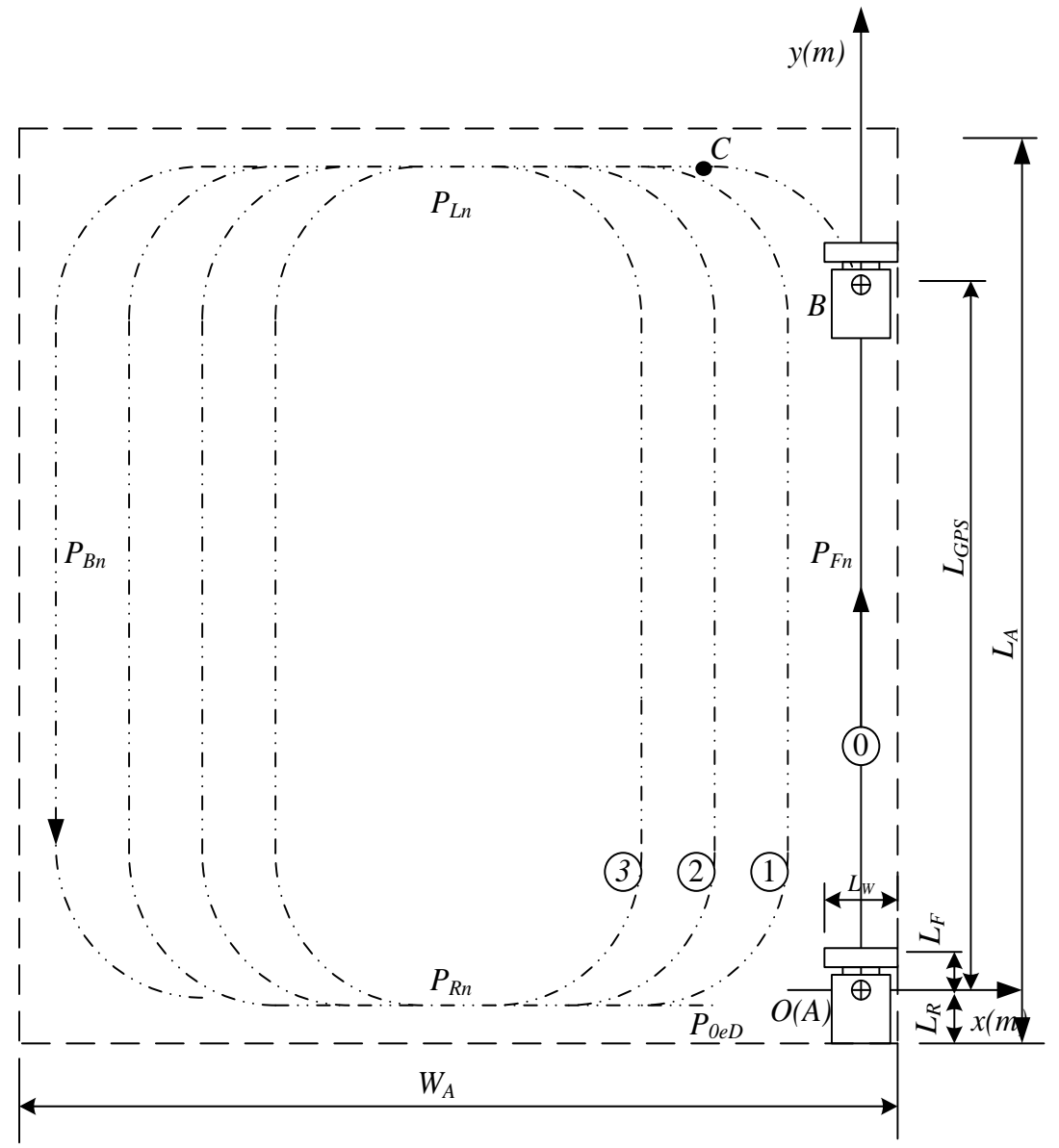

Fig.5. Coverage path planning

The forward and backward paths changed when the number of ring increasing, while the values of $y$ coordinate of the leftward and rightward paths are fixed. The four paths are list as following:

$$
\begin{aligned}
& P_{F \mathrm{n}}=-n \cdot L_{W} \\
& P_{B n}=-(2 N-n-1) \cdot L_{W} \\
& P_{L \mathrm{n}}=L_{G P S}+R+L_{F} \\
& P_{R n}=-L_{R}
\end{aligned}
$$

Where $P_{F n}, P_{B n}, P_{L n}, P_{R n}$ are paths of forward, backward, leftward, and rightward in the $n^{\text {th }}$ ring.

\subsection{Navigation control process}

The GCS executed the control process in step by step. GPS data, arriving every 200 millisecond, are the $1^{\text {st }}$ step of every control process. Latitude and longitude data were then converted into $x$ and $y$ value of the local coordinate system. Together with speed and heading angle, these data constructed the measurement vector of the Kalman filter. In the $2^{\text {nd }}$ step, the Kalman filter estimated state vector and produced smoothed data, positioning data. In the $3^{\text {rd }}$ step, the GCS did rectifying or turning action depended on which state the vehicle was currently in, row following or turning state. If the machine was in a row following state, it got current path and calculated deviation. A PID function produced control value for the electro-hydraulic valve, and then sent to the ECU2 to make a steering operation, which is an end of the $3^{\text {rd }}$ step. If the remaining distance before the end point of this path was less than turning radio $R$, the GCS sent a command of $90^{\circ}$ turning to the ECU2, meanwhile, it changed over to turning state. If the machine was in turning state, the software monitored heading angle. When the 
accumulated heading angle was $90^{\circ}$, it finished the $3^{\text {rd }}$ step too, and wait the next GPS data. After the machine crawled a cycle of forward, leftward, backward, and rightward, the cycles number added 1 , and it began to harvest the inner subregion. The head cylinder dropped down in forward and backward paths, and lifted up in leftward and rightward paths.

\subsection{Auxiliary control function}

The guidance system also includes a pair of wireless data transmission modules (433MHz, transmitting with bps of 9600 , distance less than $600 \mathrm{~m}$ ): one is inside the ECU1 and another is inside a remote control. The remote controller consists of a radio module, a LCD touch screen, and a microcomputer board, which is used for artificial intervention or control in some special cases, such as manually control the machine to get away from a muddy place, load into, or unload from a heavy truck. It also makes a operator completely leave the harvester, while stand near the machine to monitor its operation.

\section{Results and discussion}

The guidance system was installed into two combine harvesters (a XG988SE and a XG988Z, Thinker agricultural machinery). The system had been tested not only on cement road, but also on paddy fields in Dec. of 2015 and 2016, that it harvested rice crops about 16 acres at Huzhou and Ningbo. Fig. 6 is a scene of harvesting.

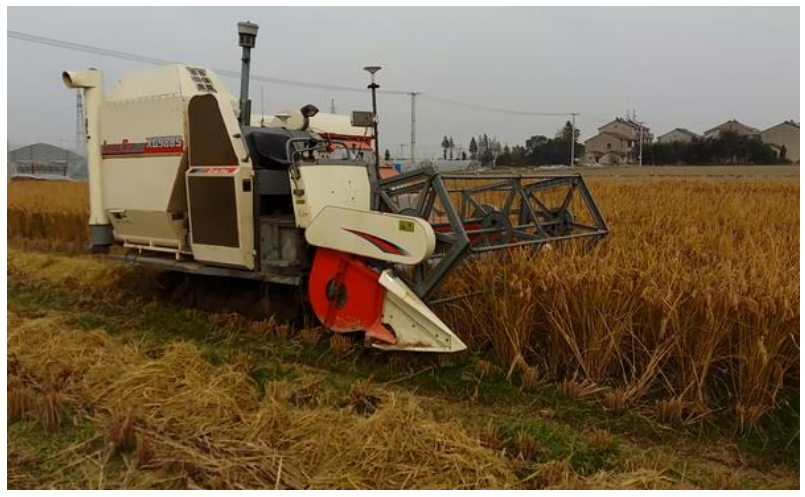

Fig. 6. The prototype of automated guided combine

\subsection{Effect of conventional path planning and improved turning method}

Field experiments showed that the guidance system has advantages over manual operation. Firstly, trajectories became a perfect straight line, that the header can be accurately cut along the edge of the cut/uncut. Secondly, path planning made a full harvest in the last path of every subregion, which improved the overall efficiency. Thirdly, the driver could stand far away from the noise and dusty machine while monitor it. Fig. 7(a) plots a trajectory of the harvesting operation, showing the advantages mentioned above. However, soil is rather muddy in some rice fields, which results in difficulty to turn $90^{\circ}$ at end of paths. Therefore the turning method was improved, called "X-turn": the harvester turned anticlockwise for 3 seconds, then it went forward straightly for 1 second. It would not stop this cycle untill a $45^{\circ}$ of heading angle changed. The harvester stopped, and then retreated with clockwise turning for 3 seconds, then went backward straightly for 1 second. It would not stop this cycle until a $45^{\circ}$ of heading angle changed., that a total $90^{\circ}$ of turning happened. Fig. 7(b) shows the trajectory of this operation. Experiments show that this method made the harvester could work in all kinds of rice crop lands. 


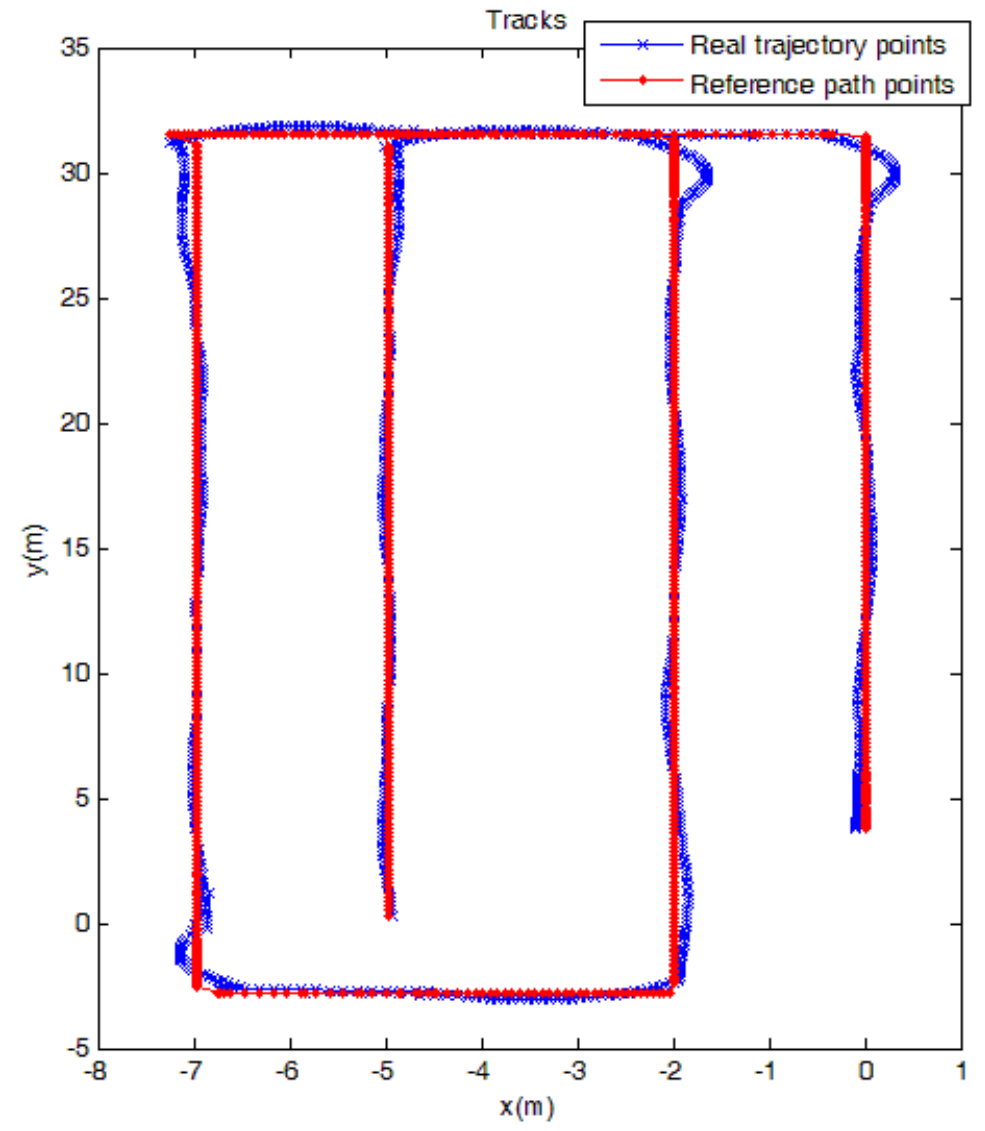

(a) trajectory of $90^{\circ}$ turning 


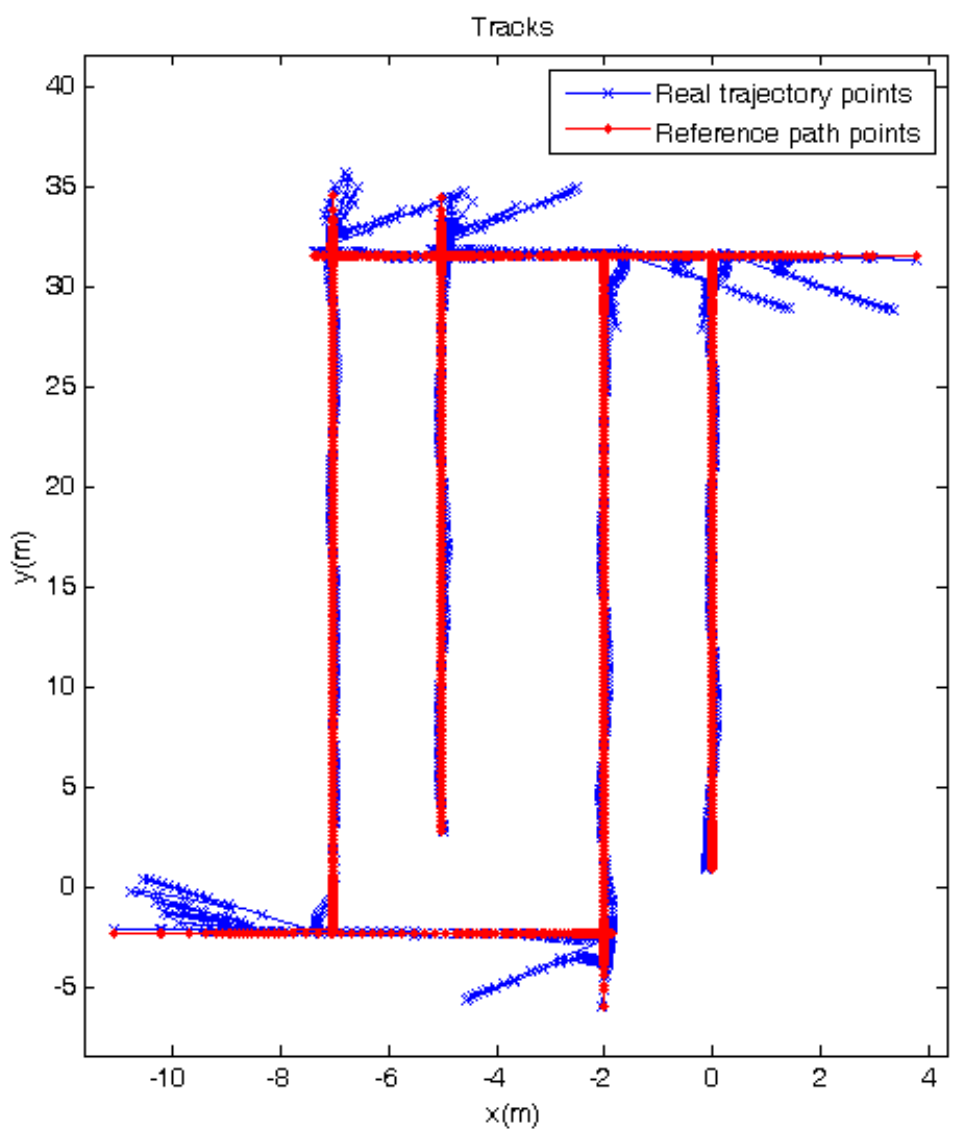

(b) trajectory of X-turn

Fig. 7 Trajectory of 2 cycles with different turning methods

\section{2 control method for rubber track}

Track control is one of key technology in this project. It shows that its control method is quite different with wheeled machinery. Firstly, the control frequency of wheeled agricultural machinery can be $5 \mathrm{~Hz}$ or more, while a tracked harvester became a matador at this frequency, and it can not meet the requirements of the smoothly harvesting operation. One solution is reducing the control frequency. Effect of different control frequency was recorded, from time interval of 0.8 second to 2 seconds. In these experiments, the automatic control started from point "C", and ended at the rightward path. Average offset and standard deviation of offset in row following is listed in Table 1. Results show that average offset are very close in all tests, ranged from $0.4 \mathrm{~cm}$ to $4.6 \mathrm{~cm}$ from time interval of 0.8 second to 1.6 second, and so to standard deviation. It seems the minimal average offset come from time interval of 1.2 second, and minimal standard deviation come from 1.6 second, and the fastest arriving to objective path come from 0.8 second. When we continued to ascend time interval to 1.8 second or 2 seconds, the control performance was significantly worse. According to the experimental data, the time interval of 1.2 second is a suitable control frequency.

Table 1. Effect of different control frequency

\begin{tabular}{|c|c|c|c|c|c|c|c|c|c|}
\hline \multirow{2}{*}{$\begin{array}{l}\text { time } \\
\text { interval } \\
(\mathrm{s})\end{array}$} & \multicolumn{3}{|c|}{ average offset $(\mathrm{cm})$} & \multicolumn{3}{|c|}{$\begin{array}{l}\text { standard deviation of } \\
\text { offset }(\mathrm{cm})\end{array}$} & \multicolumn{3}{|c|}{$\begin{array}{l}\text { After turning, distance } \\
\text { when lateral deviation is } \\
\text { less than } 10 \mathrm{~cm}(\mathrm{~m})\end{array}$} \\
\hline & $\begin{array}{c}\text { Left } \\
\text {-ward }\end{array}$ & $\begin{array}{l}\text { Back } \\
\text {-ward }\end{array}$ & $\begin{array}{l}\text { Right } \\
\text {-ward }\end{array}$ & $\begin{array}{l}\text { Left } \\
\text {-ward }\end{array}$ & $\begin{array}{l}\text { Back } \\
\text {-ward }\end{array}$ & $\begin{array}{l}\text { Right } \\
\text {-ward }\end{array}$ & $\begin{array}{c}\text { Left } \\
\text {-ward }\end{array}$ & $\begin{array}{c}\text { Back } \\
\text {-ward }\end{array}$ & $\begin{array}{l}\text { Right } \\
\text {-ward }\end{array}$ \\
\hline
\end{tabular}




\begin{tabular}{cccccccccc}
\hline 0.8 & -2.1 & -3.9 & 1.6 & 3.7 & 6.6 & 4.7 & 0.0 & 0.87 & 0.0 \\
1.0 & 2.9 & -4.6 & 1.6 & 5.9 & 7.8 & 4.7 & 2.43 & 4.5 & 0.0 \\
1.2 & 2.2 & 0.4 & 2.9 & 6.6 & 4.8 & 3.6 & 1.01 & 6.75 & 0.0 \\
1.6 & -0.4 & -3.8 & 2.0 & 5.8 & 2.4 & 4.1 & 1.17 & 0.57 & 0.0 \\
\hline
\end{tabular}

\section{3 parameters of PID control}

Tracked harvesters actually has higher efficiency on rectifying a deviation than wheeled vehicles. Heading angle of the body rotated has a linear positive relationship with the duration operated time to the electro-hydraulic valve. By using the conventional PID control algorithm, trajectories were recorded through a serial of row following experiments to evaluate effect of different PID parameters. Table 2 gives the experimental results. The results show that the appropriate value of proportional coefficient, $K_{\mathrm{p}}$ is between 0.6 0.8, where standard deviation is relatively small, and the average deviation is relatively small too, which means correction effect is obvious. The differential coefficient, $K_{\mathrm{d}}$, should not be set too big. The standard deviations are relatively large when the $K_{\mathrm{d}}$ was set to 0.4 , or 0.5 .

Table 2. effect of different PID parameters

\begin{tabular}{ccc}
\hline $\mathrm{K}_{\mathrm{p}}: \mathrm{K}_{\mathrm{d}}: \mathrm{K}_{\mathrm{i}}$ & average offset $(\mathrm{cm})$ & $\begin{array}{c}\text { standard deviation of offset } \\
(\mathrm{cm})\end{array}$ \\
$4: 2: 2$ & -4.6 & 6.0 \\
$4: 5: 1$ & -3.5 & 9.6 \\
$5: 3: 2$ & -5.5 & 5.4 \\
$5: 4: 1$ & -0.8 & 9.4 \\
$6: 2: 2$ & -3.7 & 2.0 \\
$6: 3: 1$ & -1.0 & 4.3 \\
$7: 1: 2$ & -1.2 & 3.3 \\
$8: 1: 1$ & -1.8 & 3.1 \\
$8: 2: 0$ & -2.8 & 4.2 \\
\hline
\end{tabular}

\section{Conclusions}

An automated guidance control system had been developed for tracked combine harvesters. It shows that a traditional tracked harvester could be transformed into a robot harvester after adding a guidance system and a motor-driven speeder. The lateral deviation is less than $5 \mathrm{~cm}$ when steering in row following state. Helped by path planning and automated control, the header could cut full crops in every working path, so automated tracked harvester has higher efficiency than traditional harvester.

However, the automatic guided harvester may cause unevenness of the land in end of paths. In the future, some improvement should do on this type harvesters. 1) new crawler chassis structure should be developed that one track could crawl forward while the another track crawl backward when the machine need turning a $90^{\circ}$ or more. This will reduce destruction of land; 2) main rotating parts, grain container, conveying channel should be monitored for unmanned operation.

\section{Acknowledgment}

Funds for this research was provided by the Yinzhou Science and Technology Plan Projects (2015), Ningbo Science and Technology Plan Projects (2014C100016).

\section{References}


10

1. Tillett, N. D., Hague, T.:Computer-Vision-based Hoe Guidance for Cereals - an Initial Trial. J. of Agricultural Engineering Research, 74(3),225-236(1999)

2. Han, S., Zhang, Q., Ni, B., Reid, J. F.:A guidance directrix approach to vision-based vehicle guidance systems.Computers and Electronics in Agriculture, 43(3),179-195(2004)

3. Kise, M., Zhang, Q., Rovira Más, F.:A Stereovision-based Crop Row Detection Method for Tractor-automated Guidance. Biosystems Engineering, 90(4),357-367(2005)

4. Chen, J., Torisu, R., Zhu, Z.:Study on Automatic Guidance for Tractor on Grassland. Transactions of CSAM,36(7),104-107(2005)(in Chinese)

5. Noguchi, N.,Reid, J. F.,Zhang, Q.,Will, J.D., Ishii, K.:Development of Robot Tractor Based on RTK-GPS and Gyroscope. In:2001 ASAE Annual International Meeting, pn.011195(2001)

6. Zhang, Z., Luo, X., Zhou, Z., Zang, Y. Design of GPS Navigation Control System for Rice Transplanter. Transactions of CSAM,37(7),95-98(2006)(in Chinese)

7. Zhang, F., Shin, B., Feng, X., Li, Y. Development of a prototype of guicance system for Rice-transplanter. J. Of biosystems engineering, 38(4):255-263(2013)

8. He, Z., Chen H., Tao, G., Wu S. Remoted Automatic driving control system of crawler type vehicle. Construction machine and equipment, 10,3-7(2003)(in Chinese)

9. Chen J.,Ning X.,Li Y. Fuzzy Adaptive Control System of Forward Speed for Combine Harvester Based on Model Reference. Transactions of CSAM,45(10),87-91(2014)(in Chinese)

10. Galceran, E., Carreras, M.A survey on coverage path planning for robotics. Robotics and autonomous systems, 61:1258-1276(2013) 